\title{
Pilot intervention to improve the documentation of pediatric injuries in the emergency department
}

\author{
Donald C. Voaklander, PhD;* Garnet E. Cummings, MD, MSc; $\dagger$ Kim Borden, CCHRA(C);đ \\ Carla Policicchio, BScN; $\dagger$ Joanne Vincenten, MAף
}

\begin{abstract}
Objectives: Our goal was to determine the effectiveness of an intervention aimed at improving the emergency department (ED) documentation of pediatric injuries.

Methods: All physicians and nursing staff in the ED of an urban teaching hospital and trauma centre underwent focused injury surveillance training and were instructed how to document 14 injuryspecific data elements. Pocket reminder cards were provided, and pediatric injury charts were flagged. Subsequently, random samples of pediatric injury charts were analyzed from a 3-month period prior to the intervention and from the corresponding months after the intervention. Postintervention documentation was compared to pre-intervention documentation for the 14 predefined data elements.

Results: Six of the 14 data elements were charted more frequently, and 2 less frequently during the post-intervention phase. Odds ratios ranged from $4.59(95 \% \mathrm{Cl}, 3.40$ to 6.19$)$ for charting "the presence of an adult observer" to $0.09(95 \% \mathrm{Cl}, 0.01$ to 0.76$)$ for charting "sports equipment related to the injury." The "flagging" of injury charts, as a visual reminder for clinicians to document injury data, seemed to be the most effective component of the intervention.

Conclusion: A simple intervention, consisting of staff training, chart modification, and visual flagging of charts, can increase the amount of injury information documented by ED clinicians. Efforts to improve ED charting are most likely to succeed if they include visual prompts for clinicians.

\section{RÉSUMÉ}

Objectifs: Déterminer l'efficacité d'une intervention visant à améliorer la documentation au département d'urgence des blessures pédiatriques.

Méthodes : Tous les médecins et le personnel infirmier au département d'urgence d'un hôpital universitaire en milieu urbain furent soumis à une formation de surveillance vigilante des blessures et reçurent des directives sur la façon de documenter 14 éléments de données spécifiques sur les blessures. Des aide-mémoire de poche furent distribués et les dossiers des patients pédiatriques victimes de blessures reçus à l'urgence furent marqués d'un signet. Par la suite, des dossiers de blessures pédiatriques datant d'une période de trois mois antérieure à l'intervention et de trois mois suivant celle-ci furent choisis au hasard et analysés. Les documentations pré et post-intervention furent comparées par rapport aux 14 éléments de données pré-déterminés.

Résultats : Six des 14 éléments de données furent documentés plus souvent et 2 moins souvent au cours de la phase post-intervention. Le rapport de probabilité variait entre 4,59 (IC à 95 \%, 3,40 à $6,19)$ pour l'inscription «Présence d'un adulte observateur» et 0,09 (IC à $95 \%, 0,01$ à 0,76$)$ pour I'inscription «Utilisation d'équipement de sport.» Le fait de mettre un signet aux dossiers pour rap-
\end{abstract}

\footnotetext{
*Department of Rural Health, University of Melbourne, Victoria, Australia; +Royal Alexandra Hospital, Edmonton, Alta.; ๆAlberta Centre Injury for Control and Research, Edmonton

Received: Mar. 23, 2000; final submission received: July 17, 2000; accepted: July 29, 2000.

This article has been peer reviewed.
} 
peler aux médecins de documenter les données au sujet des blessures semblait être la composante la plus efficace de l'intervention.

Conclusion: Une simple intervention impliquant la formation du personnel, la modification des dossiers et l'ajout de signets peut permettre aux urgentologues de maintenir une meilleure documentation des données sur les blessures. Les efforts pour améliorer les dossiers d'urgence sont plus susceptibles d'être couronnés de succès si ceux-ci comprennent des rappels visuels pour les cliniciens.

Key words: emergency department, documentation, surveillance

\section{Introduction}

"Surveillance" refers to the systematic collection and evaluation of disease-related data in an effort to track trends, evaluate countermeasures and devise strategies for control. In Canada, largely because of poor emergency department (ED) information systems, systematically collected injury data has historically been limited to fatalities and inpatient hospitalizations, although some EDs have attempted to improve injury surveillance. For example, selected EDs participate in the Canadian Hospitals Injury Reporting and Prevention Program (CHIRPP), which gathers detailed injury data. Unfortunately, existing data is generally not population based, ${ }^{2}$ and many clinically important injuries remain unreported. ${ }^{3,4}$

The following example illustrates the value of ED injury data. In 1999, the American Academy of Pediatrics (AAP) recommended a ban on home trampolines. ${ }^{5}$ This was based primarily on ED-derived data, ${ }^{6-11}$ which showed that at the time of injury trampoline safety regulations were generally not in effect (e.g., no spotters and multiple users) and that many trampoline injuries caused long-term activity limitation despite having required only outpatient treatment (e.g., surgery, casting). Had the AAP considered only hospitalization and mortality data, this information would have been unavailable.

In the Edmonton region, there are over 300,000 ED patient encounters annually, and 30\% of these are associated with injury. Since April 1995, all ED encounters have been recorded in an electronic database. Medical record nosologists assign ICD-9 external cause of injury (E) codes, so that injury rates can be approximated. But E codes alone are not sensitive enough to track injury trends; nor do they provide specific information about injury circumstances, particularly in the area of sports and recreation. ${ }^{12,13}$ To obtain important data regarding injury circumstances, specific cause, setting and geographic location, it is often necessary to interview patients or review charts.

Our hypothesis was that by teaching ED staff about the importance of injury surveillance and instructing them on what information should be recorded during the patient visit, we could improve the documentation of critical data elements on ED charts. Ultimately, enhanced ED data could be used to determine trends, plan injury reduction strategies and evaluate interventions. Our objective was to determine the effectiveness of an intervention designed to improve ED documentation of pediatric injuries.

\section{Methods}

\section{Setting}

The Capital Health Region includes the greater Edmonton area, a population of over 800,000 . Within this region, 6 hospital-based EDs provide the bulk of emergency care. The study intervention was conducted at an urban community teaching hospital and trauma centre that handles approximately 80,000 patients per year.

\section{Intervention}

The intervention consisted of injury surveillance training, pocket reminder cards and visible "flagging" of injury charts. In May 1997, 2 investigators (G.E.C. and C.P.) provided all ED physicians and nursing staff with specific injury surveillance training. Staff learned that injury is the leading cause of death and disability for people under 45 years and that comprehensive injury surveillance data can be used to design and evaluate measures to reduce injury frequency and severity. The concept of the injury pyramid was introduced, and the contribution of ED data to the pyramid was discussed. ${ }^{14,15}$ To improve charting, staff were then introduced to an injury documentation manual (available from the authors upon request). To minimize the burden on staff, no additional data forms were introduced; however, existing ED charts were modified by adding labels and space for injury-related data. (Table 1 summarizes the specific data elements under study.) Each physician was given a pocket card specifying the injury data to be charted and, finally, triage clerks were asked to flag the chart of each 
pediatric injury patient with a "Children's Health Program" symbol to prompt clinical staff. Data elements 1 through 10 (Table 1) were considered key items that should appear on all charts. Items 11 through 14 were only required if relevant to the specific injury. To reduce the Hawthorne effect, ${ }^{16}$ staff were not informed that their charting practices would be audited.

\section{Patients}

Patients under 17 years of age were eligible for study inclusion if they were treated during the study periods and had an ICD-9 E code in their electronic chart.

\section{Data collection}

Six hundred and forty-five "pre-intervention" charts were selected from a 3-month period (June through August) in 1996. Random sampling was based on the terminal digit of the chart number. The same process was used to select 321 post-intervention charts (flagged with the "Children's Health Program" symbol) from the corresponding months in 1997. During the selection process, it became apparent that not all pediatric injury charts had been flagged by a triage clerk prior to treatment; therefore, to assess the pres-

Table 1. Data elements included in the educational interventions

\begin{tabular}{|c|c|}
\hline Data element & Specifics \\
\hline $\begin{array}{l}\text { 1. Date of injury } \\
\text { 2. Time of injury }\end{array}$ & $\begin{array}{l}\text { Date and time as close as possible. If precise time not } \\
\text { available, state whether the injury occurred in the morning, } \\
\text { afternoon, evening or night. }\end{array}$ \\
\hline $\begin{array}{l}\text { 3. Relationship of reporting } \\
\text { individual to patient }\end{array}$ & $\begin{array}{l}\text { State who brought the child to the emergency department. } \\
\text { In many cases, individuals other than parents bring } \\
\text { children for treatment (e.g., siblings, sports coaches, } \\
\text { neighbours). }\end{array}$ \\
\hline $\begin{array}{l}\text { 4. Marital status of patient's } \\
\text { parents or guardians }\end{array}$ & $\begin{array}{l}\text { This is a socio-economic indicator generally charted at } \\
\text { admission. If not apparent, please inquire and document. }\end{array}$ \\
\hline 5. Activity at time of injury & $\begin{array}{l}\text { Text description of what the patient was doing at the time } \\
\text { of injury (e.g., playing on trampoline). }\end{array}$ \\
\hline 6. What went wrong & $\begin{array}{l}\text { Text description of what was antecedent to the cause of the } \\
\text { injury (e.g., fell off trampoline). }\end{array}$ \\
\hline 7. Actual cause of injury & $\begin{array}{l}\text { Text description of the cause of injury (e.g., landed on } \\
\text { concrete). }\end{array}$ \\
\hline 8. Location of injury & General location or environment (e.g., home, school). \\
\hline $\begin{array}{l}\text { 9. Address where injury } \\
\text { occurred }\end{array}$ & Specific address where injury occurred (e.g., 1234-23 St.). \\
\hline 10. Adult observer present & Did an adult witness the injury. Please document. \\
\hline 11. Prevention measures & $\begin{array}{l}\text { Caregivers are asked what could have been done to avoid } \\
\text { the injury. }\end{array}$ \\
\hline 12. Sports equipment used & $\begin{array}{l}\text { If the injury was sports related, was any key equipment } \\
\text { misused or absent. }\end{array}$ \\
\hline 13. Seatbelt or car-seat use & If a vehicle was involved, were seatbelts/car-seats used. \\
\hline 14. Environmental conditions & $\begin{array}{l}\text { Text description of conditions that may have impacted on } \\
\text { or caused the injury (e.g., weather, gravel on road). }\end{array}$ \\
\hline
\end{tabular}

ence of selection bias, a further random sample of 323 unflagged, post-intervention charts was reviewed. The sample size of 321 per cell provided $90 \%$ statistical power to detect a $10 \%$ improvement in documentation, ${ }^{17}$ which we felt would be clinically important.

An experienced medical record nosologist not connected to the intervention ED reviewed all charts. Data extraction reliability of the nosologist was established by one of the authors (K.B.) in pilot work prior to the main study (Kim Borden, unpublished data, 2000).

\section{Analysis}

Patient characteristics were described using means for continuous variables and percentages for categorical data. Chisquared analysis was used to determine the statistical significance of observed differences in categorical outcomes, while one-way ANOVA was used to compare age variations among groups and pre- versus post-intervention charting differences. Scheffe post-hoc analysis was used to determine the significance of specific group differences. Logistic regression analysis was used to calculate the odds that each specific data element would appear on the post-intervention chart. In the regression model, the intervention (i.e., pre vs. post) was the independent variable and the appearance of each specified data element on the chart (yes/no) was the dependent variable. Where elements appeared on the chart with an aggregate frequency $>95 \%$, no regression analysis was conducted. Group imbalances on age and diagnosis were controlled for in the regression analysis. All analyses were conducted using SPSS statistical software, and statistical significance was established at $p<0.05$.

\section{Results}

A total of 2,517 pediatric injury charts were available for review during the 2 study periods. Of these approximately $75 \%$ were flagged as per protocol. Table 2 summarizes patient characteristics for the study group. It shows that selected and nonselected charts were similar, based on patient age, sex and injury pattern, suggesting that our study group is representative of all pediatric injury patients seen at our hospital. Table 2 
also shows that post-intervention patients with flagged charts were significantly younger than pre-intervention patients and patients with unflagged charts $(p<0.001)$. In addition, the "flagged" group had a significantly higher percentage of lacerations than other study groups $(p<0.05)$. There were no significant group differences by time or day of presentation.

Table 3 shows the proportions of the pre-defined injury data elements that were recorded on pre- and post-intervention charts. For the key items (1 through 10), the mean number of documented data elements was 6.9 for control charts, 7.3 for unflagged post-intervention charts and 8.1 for flagged post-intervention charts $(p<0.001)$. All groups were significantly different from each other $(p<0.01$; Scheffe post-hoc test). Eight percent of pre-intervention charts, $11 \%$ of unflagged post-intervention charts, and $28 \%$ of flagged postintervention charts had all 10 key data elements recorded.

Table 3 also summarizes logistic regression data, estimating the odds (adjusted for age and diagnosis) that specified data elements would be documented on the post- versus pre-intervention charts. This table shows that there was significant improvement for 6 items (time of injury, activity at time of injury, location of injury [e.g., home, school], address where injury occurred, presence of an adult observer, and relevant environmental conditions), but significant deterioration for 2 items (possible prevention measures, and misuse or absence of sports equipment).

\section{Discussion}

Our data indicate that the study intervention, consisting of education, chart modification and visual flagging of injuryrelated charts, led to a significant improvement in injury documentation without the need to introduce new forms or data sheets.

However, although we improved documentation, we found that triage clerks failed to consistently flag injury charts, and we believe this reduced the intervention's effectiveness. Our data show that triage clerks were more likely to flag the charts of younger patients and patients with visible injuries (e.g., lacerations). This inconsistency set up a natural experiment, which allowed us to compare flagged versus unflagged charts in the post-intervention phase. Table 3 shows that documentation was substantially better on flagged charts, with higher post-intervention odds ratios and greater percentage improvements. Table 3 also shows that the items for which documentation failed to improve in the post-intervention phase were already well documented in the pre-intervention phase, suggesting little potential for improvement.

Of note, an average of 6.9 (of 10) key items appeared on pre-intervention patient charts. This increased to 7.3 items on unflagged and 8.2 items on flagged post-intervention charts. Similarly, only $8 \%$ of pre-intervention charts had all 10 key items documented, but this increased to $11 \%$ for

Table 2. Characterstics of pre- and post-intervention pediatric injury patients

\begin{tabular}{|c|c|c|c|c|c|}
\hline \multirow[b]{2}{*}{ Characteristic } & \multirow[b]{2}{*}{$\begin{array}{c}\text { Pre-intervention } \\
\text { (control) patient, } \\
n=645\end{array}$} & \multicolumn{2}{|c|}{ Post-intervention patients } & \multirow[b]{2}{*}{$\begin{array}{c}\text { Total charts } \\
\text { reviewed, } \\
n=1,289\end{array}$} & \multirow{2}{*}{$\begin{array}{c}\text { Charts } \\
\text { not selected } \\
\text { for review, } \\
n=1,228\end{array}$} \\
\hline & & $\begin{array}{c}\text { Patients with } \\
\text { unflagged charts, } \\
n=323\end{array}$ & $\begin{array}{c}\text { Patients with } \\
\text { flagged charts, } \\
n=321\end{array}$ & & \\
\hline Age $(\text { year } \pm S D)^{*}$ & $8.2 \pm 5.1$ & $9.1 \pm 5.0$ & $6.6 \pm 4.6$ & $8.1 \pm 5.0$ & $8.0 \pm 5.4$ \\
\hline Sex (\% male $)$ & 62.8 & 57.9 & 64.2 & 61.9 & 60.3 \\
\hline \multicolumn{6}{|l|}{ Diagnosis (\%) } \\
\hline Fractures & 14.4 & 19.2 & 13.7 & 15.4 & 16.9 \\
\hline Dislocations & 0.9 & 2.8 & 3.1 & 1.9 & 1.5 \\
\hline Sprains / strains & 9.0 & 9.3 & 7.2 & 8.6 & 9.4 \\
\hline Lacerations+ & 22.2 & 23.2 & 29.9 & 24.4 & 19.1 \\
\hline Contusions & 17.2 & 18.3 & 18.7 & 17.8 & 13.3 \\
\hline Foreign body & 3.4 & 5.6 & 1.2 & 3.4 & 2.5 \\
\hline Burns & 1.4 & 1.5 & 1.9 & 1.6 & 0.8 \\
\hline Concussion & 3.7 & 2.8 & 2.5 & 3.2 & 2.0 \\
\hline Superficial & 5.6 & 4.6 & 3.7 & 4.9 & 9.9 \\
\hline $\begin{array}{l}\text { Other / Not } \\
\text { specified }\end{array}$ & 22.2 & 12.7 & 18.1 & 18.8 & 24.7 \\
\hline \multicolumn{6}{|l|}{$* p=<0.001$} \\
\hline$+p=<0.05$ & & & & & \\
\hline
\end{tabular}


unflagged and $28 \%$ for flagged post-intervention charts. These data demonstrate that our simple intervention can enhance charting quality and that visual cues (flagging) are probably the most important component of the intervention.

It is interesting that the documentation of "prevention measures" (item 11) was substantially worse after the intervention. This may be a chance effect or it could have occurred because the enhanced injury data collection process created a time constraint that led clinicians to omit a "touchy" subject (i.e., what the caregiver could have done to prevent or mitigate the injury). Certainly, in a busy ED, there is a ceiling on the amount of time clinicians can spend with a patient and the amount of information they can be expected to gather.

ED injury documentation is problematic, and there is no established minimal data set. ${ }^{2,18-20}$ Consequently, injury data are collected with variable success. In one child injury surveillance system, Beattie ${ }^{21}$ reported that $65 \%$ of charts had complete data but did not itemize the data points studied. Christopher and colleagues ${ }^{22}$ evaluated the documentation of 15 injury variables on $669 \mathrm{ED}$ pediatric injury charts. In this study, the mean number of variables documented was 6.2 ( 8 of 15 was defined as acceptable), and only 1 chart documented all 15. Schwartz and coworkers ${ }^{20}$ reviewed 109 charts and found that only $46 \%$ of these had cause-of-injury information recorded.

Others have studied various interventions to improve injury charting. Pre-formatted charts for ED data collection have shown promise, ${ }^{23-25}$ particularly to improve patient history documentation. In 1 study, pre-formatted charts increased the proportion of charts judged as "complete" from $60 \%$ to $78 \%{ }^{23}$ In another study, complaint-specific charts for laceration and closed head injury failed to improve the documentation of injury mechanism but did improve other clinical documentation..$^{24}$ In 1994, Wallace and colleagues ${ }^{25}$ reported that the use of a specialized form improved ED head injury documentation substantially.

\section{Limitations and future questions}

This study was conducted at a single institution, and it is possible that physicians in other settings might respond dif-

Table 3. Data charting, by element, for pre- and post-intervention charts $(n=1,289)$

\begin{tabular}{|c|c|c|c|c|}
\hline \multirow[b]{3}{*}{$\begin{array}{c}\text { Pre-intervention, } \% \\
(n=645)\end{array}$} & \multicolumn{4}{|c|}{ Post-intervention } \\
\hline & & ed $(n=323)$ & & $d(n=321)$ \\
\hline & $\%$ & $\begin{array}{c}\text { Odds ratio } \\
(95 \% \mathrm{Cl})\end{array}$ & $\%$ & $\begin{array}{c}\text { Odds ratio } \\
(95 \% \mathrm{Cl})\end{array}$ \\
\hline
\end{tabular}

\begin{tabular}{|c|c|c|c|c|c|}
\hline \multicolumn{6}{|c|}{ Data elements with no significant post-intervention change in documentation } \\
\hline Date of injury & 100 & 100 & & 100 & \\
\hline $\begin{array}{l}\text { Relationship of reporting } \\
\text { individual to patient }\end{array}$ & 99.1 & 100 & & 99.4 & \\
\hline $\begin{array}{l}\text { Marital status of } \\
\text { parent/guardian }\end{array}$ & 91.5 & 90.4 & $0.86(0.54-1.37)$ & 91.3 & $0.99(0.61-1.60)$ \\
\hline What went wrong & 85.6 & 83.0 & $0.82(0.57-1.18)$ & 87.5 & $1.11(0.74-1.67)$ \\
\hline Actual cause of injury & 99.7 & 99.7 & & 99.7 & \\
\hline $\begin{array}{l}\text { Seatbelt or car-seat use } \\
(n=72)\end{array}$ & 80.4 & 86.4 & $1.47(0.28-7.87)$ & 75.0 & $0.67(0.04-1.47)$ \\
\hline \multicolumn{6}{|c|}{ Data elements with significant post-intervention improvement in documentation } \\
\hline Time of injury & 37.3 & 46.9 & $1.49(1.13-1.96)^{*}$ & 67.5 & $3.94(2.94-5.28)$ \\
\hline Activity at time of injury & 69.9 & 75.2 & $1.26(0.92-1.72)$ & 92.5 & $3.28(2.07-5.12)^{*}$ \\
\hline Location of injury & 50.5 & 59.8 & $1.57(1.19-2.07)^{*}$ & 71.0 & $2.29(1.70-3.07)^{*}$ \\
\hline $\begin{array}{l}\text { Address where injury } \\
\text { occurred }\end{array}$ & 34.3 & 41.5 & $1.54(1.15-2.05)^{*}$ & 53.9 & $2.08(1.57-2.77)^{*}$ \\
\hline Adult observer present & 22.0 & 32.2 & $1.68(1.24-2.28)^{*}$ & 53.6 & $4.59(3.40-6.19)^{*}$ \\
\hline Environmental conditions & 13.5 & 20.4 & $1.57(1.09-2.24)$ & 23.4 & $2.19(1.54-3.12)^{*}$ \\
\hline \multicolumn{6}{|c|}{ Data elements with significant post-intervention deterioration in documentation } \\
\hline Prevention measures & 21.4 & 18.9 & $0.81(0.57-1.14)$ & 12.1 & $0.56(0.38-0.83)^{*}$ \\
\hline $\begin{array}{l}\text { Sports equipment used } \\
(n=203)\end{array}$ & 98.8 & 88.2 & $0.09(0.01-0.76)^{*}$ & 94.4 & $0.17(0.02-1.65)$ \\
\hline
\end{tabular}


ferently to a similar intervention. Because our controls were historical rather than concurrent (before-after design), it is conceivable that other factors (e.g., public injury awareness programs) could also have affected our outcome of interest; however, the authors know of no such confounding factors. A significant limitation is that we measured the outcome of the intervention at one point in time, therefore we cannot say whether improved charting will be sustained. Finally, it is of concern that, despite the intervention, many injury charts were not flagged by triage clerks. Investigators attempting similar interventions will need to develop mechanisms to address this problem and should emphasize the key role that triage clerks have in improving chart quality.

In the future, we intend to perform data audits over longer periods to determine the optimum timing for refresher training. In addition, we will extend this intervention into the other 5 regional EDs and monitor ongoing program effectiveness.

\section{Conclusions}

A simple intervention, consisting of staff training, chart modification and visual flagging of charts, can increase the amount of relevant injury information documented by ED clinicians while imposing minimal additional burden. Efforts to improve ED charting are most likely to succeed if they include visual prompts for clinicians.

Acknowledgement: This study was sponsored by the KIDSAFE Connection of the Children's Health Centre of Capital Health in collaboration with the Royal Alexandra Hospital. The Department of Rural Health is funded by a grant from the Commonwealth Department of Health and Aged Care, Canberra, Australia.

\section{References}

1. Last JM. A dictionary of epidemiology, 3rd ed. Toronto: Oxford University Press; 1995.

2. Laboratory Centre for Disease Control. Children's Hospitals Injury Research and Prevention Program (CHIRPP). Technical report \#2. Ottawa: The Centre; 1991.

3. Baker SP, O’Neill B, Ginsburg MJ, Guohua LI. The injury fact book, 2nd ed. New York: Oxford University Press; 1992.

4. Deane M. Child accident data: Accessible and available? J Public Health Med 1993;15:226-8.

5. Trampolines at home, school, and recreational centers. American Academy of Pediatrics. Committee on Injury and Poison Prevention and Committee on Sports Medicine and Fitness. Pediatrics 1999;103:1053-6.

6. Woodward GA, Furnival R, Schunk JE. Trampolines revisited a review of 114 pediatric recreational trampoline injuries. Pediatrics 1992;89:849-54.

7. Larson BJ, Davis JW. Trampoline-related injuries. J Bone Joint Surg [Am] 1995;77:1174-8.
8. Hume PA, Chalmers DJ, Wilson BD. Trampoline injury in New Zealand: emergency care. Br J Sports Med 1996;30:327-30.

9. Furnival RA, Street KA, Schunk JE. Too many pediatric trampoline injuries. Pediatrics 1999;103:e57.

10. Smith GA. Injuries to children in the United States related to trampolines, 1990-1995: a national epidemic. Pediatrics 1998; 101:406-12.

11. Smith GA, Shields BJ. Trampoline-related injuries to children. Arch Pediatr Adolesc Med 1998;152:694-9.

12. Williams JM, Furbee PM, Prescott JE, Paulson DJ. The emergency department log as a simple injury-surveillance tool. Ann Emerg Med 1995;25:686-91.

13. Smith GS, Langley JD. Drowning surveillance: How well do E codes identify submersion fatalities? Injury Prev 1998;4:135-9.

14. Guyer B. Injury prevention: meeting the challenge. New York: Oxford University Press; 1989.

15. Monash University Accident Research Centre. Injury research and prevention: a text. Melbourne: The Centre; 1995.

16. Campbell JP, Maxey VA, Watson WA. Hawthorne effect: implications for prehospital research. Ann Emerg Med 1995;26:590-4.

17. Cohen J. Statistical power analysis for the behavioral sciences. New Jersey: Lawrence Erlbaum Associates; 1988.

18. Langlois JA, Buechner JS, O’Connor EA, Nacar EQ, Smith GS. Improving the $\mathrm{E}$ coding of hospitalizations for injury: Do hospital records contain adequate documentation? Am J Public Health 1995;85:1261-5.

19. Schwartz DF. It is time to get serious about childhood injury surveillance in the United States [editorial]. Am J Prev Med 1995; 11:134-5.

20. Schwartz RJ, Boisoneau D, Jacobs LM. The quality of cause-ofinjury information documented on the medical record: an appeal for injury prevention. Acad Emerg Med 1995;2:98-103.

21. Beattie TF. An accident and emergency based child accident surveillance system: Is it possible? J Accid Emerg Med 1996; 13:116-8.

22. Christopher NC, Anderson D, Gaertner L, Roberts D, Wasser TE. Childhood injuries and the importance of documentation in the emergency department. Pediatr Emerg Care 1995;11:52-7.

23. Humphries T, Shofer FS, Jacobson S, Coutifaris C, Stemhagen A. Preformatted charts improve the documentation in the emergency department. Ann Emerg Med 1992;21:534-40.

24. Wrenn K, Rodewald L, Lumb E, Slovis C. The use of structured, complaint-specific patient encounter forms in the emergency department. Ann Emerg Med 1993;22:805-12.

25. Wallace SA, Gullan RW, Byrne PO, Bennett J, Perez-Avila CA. Use of a pro forma for head injuries in the accident and emergency department - the way forward. J Accid Emerg Med 1994;11:33-42.

Correspondence to: Dr. Don Voaklander, Department of Rural Health, University of Melbourne, PO Box 6500, Shepparton, Victoria 3632, Australia; tel +61 35831 6036, fax +61 35831 6435; don@unimelb.edu.au 